\title{
Má consciência e mal-estar civilizacional, do niilismo a um mundo possível
}

\author{
Considerações a partir de Segunda Dis- \\ sertação de Para a Genealogia da Moral
}

Bad conscience and civilizational malaise,
from nihilism to a possible world.

Considerations from Second Dissertation On the Genealogy of morals

Adilson Felicio Feiler

Professor do PPG de filosofia da UNISINOS

Resumo: A má consciência é produzida por uma civilização niilista. Na Segunda Dissertação da Para a genealogia da moral Nietzsche detecta que o problema da consciência é, antes de tudo, um problema cultural e não individual. A perda da ênfase sobre o indivíduo, na massa uniforme da coletividade, conduz ao abandono dos traços que marcam a grandeza potencial da ação. Sem o traço individual equivale a entrega ao conformismo moral gregário, a direção de degenerescência da consciência. Neste sentido, a má consciência se revela como problema oriundo de uma civilização enferma, niilista; sua superação aponta para um mundo possível.

Palavras-Chave: Nietzsche, má consciência, cultura, moral, civilização 
Abstract: The bad conscience is produced by a nihilist civilization. In the Second Dissertation of On the genealogy of Morals Nietzsche detects that problem of conscience is, before everything, a cultural and not an individual problem. The loss of emphasis about the individual, in the uniform mass of community, lead to abandon of traces that appoint the potency largeness of action. Without the individual trace amounts to abandon itself to moral gregarious conformism, direction to conscience's degeneracy. In this sense, the bad conscience reveals itself as problem coming from a sick, nihilist civilization; its overcoming points to a possible world.

Keywords: Nietzsche, bad conscience, culture, moral, civilization

A má consciência é um movimento que se origina de uma Ivisão estreita, da separação do que é a própria consciência, e que se torna ainda pior por ignorar sua genealogia e o conhecimento de seu passado. Daí a importância de se desenvolver uma segunda visão (NIETZSCHE, GM, § 04, V, 1999, p. 297) que compreende a história da moral. É este, pois, o caminho que Nietzsche percorre, diferentemente de Freud que, ao tratar deste problema do mal estar civilizacional, como mostra Renee Volpato Viaro, “(...) busca fazer de seu mal-estar a fundamentação da relação tortuosa entre indivíduo e cultura, Nietzsche, por sua vez, busca com sua moral investigar sua própria origem, de maneira a criticar o valor dos valores morais." (VIARO, 2012, p. 375).

As relações contratuais que se estabelecem mediante promessas, aquelas de o devedor saldar a sua dívida para com o credor, se constroem na base da memória. Está aí de novo, o não esquecimento como dispositivo cristalizador anímico, responsável por imprimir na consciência os eventos, fatos e situações vividos nas relações sociais. Ao sufocar os aspectos singulares e individuais a sociedade conduz o homem à decadência: "(...) a questão social é uma consequência da decadência." (NIETZSCHE, FP 1887-9, 14 (86), XIII, 1999, p. 265). Dessa forma são estes mecanismos impostos por esta estrutura social com uma abrangência cultural e civilizacional. Por isso, Nietzsche, 
a esse respeito, se pronuncia: "Nesta esfera, a das obrigações legais, está o foco de origem desse mundo de conceitos morais: 'culpa', 'dever', 'sacralidade do dever'. (NIETZSCHE, GM, § 06, V, 1999, p. 300).

Portanto, o não cumprimento do dever remonta toda a história da cultura superior, o emprego da vingança, do fazer sofrer e da crueldade. A sociedade antiga gozava de prazer ao vê-la fazer sofrer. Era uma verdadeira festa, um espetáculo, como atestam as execuções dos cristãos, mas apenas, uma atividade essencialmente pública, cuja imaginação passava pelos espetáculos e festas e, consequentemente, pelo sofrimento. Neste sentido, o filósofo alemão parece reconsiderar o valor do sofrimento como um chamariz à vida, já que do sofrimento todos podem sair mais fortes, diferentemente daqueles que se enclausuram na submissão da fraqueza com pessimismo e vergonha de seus instintos. Contudo, o grande problema foi o fato de o ser humano ter buscado um sentido para o sofrimento que não fosse o sentido da vida, o acúmulo de forças, mas a invenção de uma divindade para assim justificar o sofrimento, todo o mal e a própria vida. A humanidade se viu obrigada a buscar, na divindade, uma justificativa para o seu sofrimento, justificativa de um rebanho movido pela culpa.

A origem primordial do sentimento de culpa se dá na mais antiga relação interpessoal entre credor e devedor. Quando a humanidade, movida por sentimentos baixos, resolve medir o ser humano segundo um critério de equivalência valorativa, a saber, o altruísmo, sucede que “(...) o egoísmo 'tanto quanto o altruísmo não passam de uma ficção popular." (NIETZSCHE, FP 1887-9, 11 (83) (339), XIII, 1999, p. 39). Ficção esta que é provocadora da tortura, da consciência, portanto, da má consciência. A ficção popular age como um neutralizador da pluralidade de acontecimentos situados no interior do organismo punindo-os da maneira mais perversa, de modo a preservar aqueles pré-conceitos, ideias e aparências que se querem afirmar. Destes resquícios valorativos se parte para as grandes generalizações em que tudo pode ser pago por um preço determinado (NIETZSCHE, GM, V, 1999, p. 305). 
Neste estágio, portanto, a justiça é considerada a acomodação a um compromisso de igualdade entre si. É um compromisso que um indivíduo contrai para com uma comunidade, na qual está implicada toda uma sorte de obrigações, benefícios e vantagens. Toda a rebelião que este indivíduo impetra contra a comunidade faz dele um criminoso que atenta contra o ser credor. Diante disso, a sua sorte (castigo) passa a ser o banimento do Estado, para lançá-lo ao estado selvagem. No entanto, à medida em que o poder desta comunidade for aumentando, tanto mais livre estará esse indivíduo da ira do credor. Com isso, há uma evolução do direito penal que dissocia o criminoso do seu ato. O peso institucional de uma coletividade torna-a tão segura de si que nada a pode abalar e, sequer representar alguma ameaça. Contudo, ao sentir essa fraqueza ela torna a impetrar uma maior dureza no emprego da lei, mediante o controle e o regramento de seus indivíduos. Enquanto a força criar mecanismos de segurança a ponto de se viver além do bem e do mal, a ponto de suprimir a própria justiça, a fraqueza fará com que se busque proteção numa atitude melindrosa e vingativa. É, pois, justamente esta sacralização da vingança, pelo emprego dos afetos reativos, que faz com que a justiça seja promovida. Pois, quando não há mais força, e sim fraqueza, deixa-se com que o ressentimento tome as rédeas da situação. Com isso, se permite à má consciência turvar a liberdade, condenando tudo o que é ativo, violento e excessivo. (NIETZSCHE, GM, § 11, V, 1999, p. 311). Uma consciência que é fruto de uma cultura, de uma civilização. Mas como é possível falar em sociedade, esquecendo-se de que ela é constituída de indivíduos? Com isso não estaríamos acentuando o aspecto individual ao invés do coletivo? Onde estaria a gênese da má consciência, no indivíduo ou na cultura?

Damos seguimento às nossas análises sobre o problema da má consciência, mediante suas determinações micro e macroestruturais, através da esfera dos mecanismos humanos internos e externos sócio culturais. Para tanto nos utilizaremos de Para a Genealogia da Moral que, no dizer de Otfried Höffe (HÖFFE, 2004, p. 07), constitui um dos auges da arte argumentativa de Nietzsche. Juntamente com a Genealogia, tomaremos 
os Fragmentos Póstumos referentes aos anos 1887 a 1889. Principiamos nosso itinerário pelo enfoque que a Segunda Dissertação da Genealogia da Moral atribui à justiça enquanto prática singular. Em seguida destacaremos os mecanismos culturais desencadeadores da culpa enquanto dispositivo gregário. Por fim, tomaremos a má consciência enquanto mecanismo institucional psicológico.

\section{A má consciência enquanto prática singular da justiça}

Nietzsche atribui o senso autêntico de justiça ao homem justo (NIETZSCHE, GM, § 11, V, 1999, p. 312), e não a uma estrutura social de justiça. Para ele a justiça, no sentido mais genuíno, parte de uma prática singular e não de uma regra socialmente determinada. Esse homem justo permanece justo para além de todos aqueles que querem impetrar-lhe injustiças. Ele não se deixa vencer pelo sentimento de vingança e, com isso, o resultado é o de um poder mais forte de se impor sobre os mais fracos. Essa fortificação da cultura faz com que o estado de direito seja um estado de exceção, no qual se propicia a criação de maiores e mais fortes unidades de poder (NIETZSCHE, § 11, V, 1999, p. 313) e não - como quer Dühring - fazer com que uma vontade de vida considere toda a outra vontade como igual. Isso seria operar uma uniformização deletéria ao princípio sob o qual a vida se afirma, já que a força e a luta se estabelecem entre desiguais. É justamente a partir deste sentido de luta que compreendemos a origem e a finalidade de inúmeras formas e instituições como é o caso do castigo e do Direito. Quanto ao castigo,

(...) o autor opera uma distinção simples, porém fundamental: ao versar sobre o castigo, explicita a diferença entre origem e finalidade. Nietzsche atenta para o entendimento corriqueiro (mesmo para alguns estudiosos) que descobre no castigo uma finalidade qualquer por exemplo, a vingança e coloca esse fim na origem, na causa dele, como se o castigo tivesse sido criado justamente para vingar ou punir. Quebrando com essa lógica, o autor aponta para a significativa distância entre a causa de emergência de algo - sua origem - e a aplicação que lhe é dada - sua finalidade. (VIARO, 2012, p. 378). 
Além de se pensar a sua finalidade sob a égide de uma causa externa, assim como o seu progresso lógico rumo a uma meta, não há outra forma de se pensar a sua origem e finalidade senão mediante uma sucessão de processos de assenhoramento e subjugação pela introdução de novos sentidos que sofrem interpretações sucessivas, nos quais estão implicados a intercalação de ações e reações, de forças e resistências na concepção organicista da vida. Esta concepção compreende a vida como vontade de potência com a primazia da espontaneidade, da agressividade, da expansão e da criação. Na base da compreensão da vida está uma crítica cultural, que, como fruição da vida, assume a dimensão anímica, puramente individual, para além da compreensão das coisas como uniformização estática, direitos iguais, justiça forjada pelo rebanho. A própria noção de desigualdade social é condição para a existência dos direitos. Oswaldo Giacoia Junior recorda que: "Nesse processo ela (a crítica cultural) é tomada de pânico quando a promessa de justiça e igualdade universal de direitos começa a ser cobrada pelas massas dos novos escravos rebelados." (GIACÓIA, 2014, p. 64)

Desse modo, se depreendem da compreensão de Nietzsche duas formas de se entender a origem de temas como o castigo; uma estática, que vê no fenômeno um costume, um ato consagrado na cultura, e outra fluida, que procura compreender o fenômeno mediante o seu sentido. Este sentido é incapaz de ser capturado mediante os mecanismos social e culturalmente estabelecidos. Dentre estes últimos se destaca, de maneira particular, a compreensão do castigo como um instrumento provocador de uma reação psíquica denominada má consciência. Scott Greer recorda que a concepção de “(...) 'má consciência como parte da maior gênese da consciência e da consciência moral" (GREER, 2002, p. 06) tem na moral civilizada a internalização da punição."

Logo, a punição, pela repreensão dos instintos, desperta no homem o sentimento acentuado de culpa (NIETZSCHE, § 14, V, 1999, p. 318), típico de uma consciência popular. "De acordo com Nietzsche, esta 'internalização' do instinto provoca o sentimento de culpa." (GREER, 2002, p. 08). Por essa razão 
“(...) toda a práxis da reprodução psíquica precisa ser reconduzida a uma base fisiológica: 'o remorso' como tal é um obstáculo para a convalescença - é preciso buscar pesar tudo por meio de novas ações, e o mais rápido possível, a enfermidade da autotortura..." (NIETZSCHE, FP 1887-9, 14 (155), XIII, 1999 p. 339). Enquanto compatibilizada a sua dimensão física, a ação é força, pois responde aos comandos instintuais que se experiencia. Ao passo que, ao reduzir a ação ao fator psicológico, se debilita a sua capacidade de atuar, revertendo-a em uma consciência enferma, que a todo o instante lhe provoca remorso, o qual está na "(...) origem do movimento pela igualdade social." (NIETZSCHE, FP 1885-7, 8 (7), XII, 1999, p. 337). Como o mecanismo da culpa é ativado pelo dispositivo do castigo?

\section{O castigo como dispositivo de aumento da culpa}

Se formos analisar a situação dos autênticos prisioneiros e criminosos, vemos que o castigo não opera neles um autêntico remorso e sentimento de culpabilidade, mas, pelo contrário, os torna ainda mais frios e enrijecidos, com aumento de força e distância. Este modelo de correção, pelo castigo, tem feito eclodir o sentimento de culpa. Neste terreno, portanto, a má consciência não cresceu.

Portanto, o atual modelo penitenciário pune atos, ou seja, permanece naquela maneira estática de se compreender o castigo, não se lidando com um culpado e sim com um causador de danos. Logo, se está distante da compreensão fluida do castigo. $\mathrm{O}$ verme roedor da má consciência permanece distante da compreensão do castigo que se depreende do atual modelo penitenciário. Se o objetivo das casas de detenção é despertar má consciência, culpa e remorso nos detentos, é preciso admitir que este foi frustrado. Constatamos o quanto é equivocado o modelo penitenciário que temos, pois crê realizar algo que, na verdade, não o cumpre, insistindo em sua compreensão estática do castigo, como se fosse simplesmente um ato, ou costume, portanto algo típico de uma interpretação moral. Na medida em que esta foi submetida a uma compreensão fluida, dinâmica se poderá atingir o nível psicológico, anímico, ou 
seja, o sentimento de culpa. Nisso consiste a tarefa mais árdua, pois faz com que se depare com o sentimento psicológico do niilismo frente a frente. "O niilismo como estado psicológico precisará entrar em cena em primeiro lugar, quando tivermos buscado um 'sentido' em todo acontecimento, que não está aí." (NIETZSCHE, FP 1887-9, 11(99) (351), XIII, 1999, p. 46). O niilismo, em seu estado psicológico, é a tentativa de dar sentido ao sem-sentido e a consequente conscientização de que todo o esforço foi em vão. "O niilismo como estado psicológico entra em segundo lugar na sistematização, mesmo numa organização em todo acontecimento e sob todo acontecimento." (NIETZSCHE, FP 1887-9, 11(99) (351)., XIII, 1999, p. 47).

O niilismo como estado psicológico tem ainda uma terceira e derradeira forma. Dadas essas duas intelecções, a de que com o devir nada é obtido e a de que não vigora por debaixo de todo o devir nenhuma grande unidade, na qual o singular pudesse submergir completamente como um elemento de um valor supremo: então ainda resta como refúgio condenar todo o mundo do devir com ilusão e inventar um mundo que se encontra para além desse mundo do devir, um mundo verdadeiro. Contudo, logo que o homem descobre como esse mundo só ganhou espaço por necessidades psicológicas e como ele não tinha razão alguma para tanto, surge a última forma de niilismo, que encerra em si a descrença em um mundo verdadeiro. (NIETZSCHE, FP 1887-9, 11(99) (351), XIII, 1999, p. 47-8).

Esta derradeira forma de niilismo psicológico consiste em um se deparar com o nada do além-mundo do devir. Deparar-se com esse mundo não é nada senão caos e aparência. E isto significaria tornar-se passivo, incapaz de agir diante do turbilhão niilista. A extração artificial conceitual da ação provoca o esvaziamento da ação. (NIETZSCHE, FP, 1887-9, 11(96) (348, XIII, 1999, p. 44).

Frente a essa forma radical de niilismo se coloca uma compreensão minimizada deste que vê o castigo como o que considera o ser humano como um fragmento do destino que procura despertar medo, autocontrole e mordida de consciência. Contudo, longe de melhorá-lo o torna ainda pior e até tolo. (NIETZSCHE, § 15, V, 1999, p. 321). Isso porque o interdito, a norma, a moral social culturalmente estabelecidas atuam no homem no sentido de inibir a sua capacidade de agir, de esti- 
mular a luta e a provocação dos instintos, fazendo com que seja "(...) encerrado no âmbito da sociedade e da paz." (NIETZSCHE, § 16, V, 1999, p. 322).

Aqui Nietzsche dá pistas claras para se constatar a origem da má consciência. A sociedade com os seus mecanismos de interdição, regramento e adestramento tornam a consciência uma prisão dos instintos. Ao invés de se exteriorizarem, voltam-se para dentro, como uma força contra o próprio homem. "Todos os instintos que não se descarregam para fora voltam-se para dentro - isto é o que se chama de interiorização do homem: é assim que cresce no homem o que depois se denomina sua 'alma'." (NIETZSCHE, § 15, V, 1999, p. 322). Alberto Carlos Onate, sobre este processo de interiorização da consciência, alega: "A 'interiorização' é fruto de um imenso esforço conciliador, apaziguador, que arrefece e acaba por interditar a descarga dos instintos favoráveis à violência, à conquista; privados do canal de expressão externa, eles se resignam a desenvolver um périplo interno em cuja brecha se instaura o estado consciente." (ONATE, 2000, p. 35).

É este o movimento do qual se origina a má consciência. Portanto, é todo um movimento orquestrado pelo castigo, impetrado pelas forças organizadas pelo Estado. Este, na leitura do filósofo alemão, tem sua origem associada ao conflito e à guerra. Porém, não é naquele mesmo enquadramento teórico de guerra tal como entendido na formação do Estado Grego. É uma guerra que, em última análise, se impetra contra si mesmo. Este faz com que o homem sofra de uma doença que é o próprio homem. O homem é levado, portanto, a ter que se curar de si mesmo; um movimento faz dele um caminho, uma promessa que tem como meta não mais ele, mas sim os cerceamentos morais institucionalizados. Em que medida os dispositivos institucionais atuam no sentido de provocarem má consciência?

\section{A má consciência enquanto mecanismo institu- cional psicológico}

Através destes cerceamentos morais nasceu a má consciência que, com as suas rupturas coercitivas, abruptas e violen- 
tas, promovem uma anulação de tudo o que constitui iniciativa individual. José Antônio Feitosa Apolinánio, em comentário aos critérios hermenêuticos sobre a cultura e civilização no pensamento do filósofo de Naumburg, “(...) aponta o que veio a ser o processo civilizatório, sinônimo de uma ininterrupta história de entorpecimento dos impulsos vitais ligados a atuação da vontade de poder." (APOLINÁRIO, 2013, p. 04).

Com isso, a liberdade é calcada aos pés pelos mais variados aparatos sociais institucionalizados que se creem justificados eternamente. Nestes aparatos institucionalizados a má consciência tem o seu solo que, como parasitismo da mudança, da diferença e da diversidade, se resigna no engessamento ordenador pacifista que "(...) afastou de si os meios de conduzir a guerra com ações e com armas: um tipo carunchoso de 'escolhidos', apóstolos da paz.” (NIETZSCHE, FP 1887-9, 11(297), XIII, 1999, p. 124).

Neste ordenamento o que conta é o valor do bem comum e não o do bem individual, é o que Nietzsche acentua quando defende o egoísmo, o não importar-se por si mesmo, e - mais que isso - o impetrar mal tratos contra si mesmo.

Portanto, na lógica da má consciência se elimina o indivíduo em função do altruísmo. O valor do indivíduo é sacrificado em nome do

(...) instinto de rebanho, por conseguinte - um poder que se tornou agora soberano - é algo fundamentalmente diverso do instinto de um sociedade aristocrática (...) A valoração com a qual julgamos hoje as formas diversas da sociedade é exatamente a mesma que atribui à paz um valor mais elevado do que a guerra ... (...) A vida é uma consequência da guerra; a sociedade mesma, um meio para a guerra. (NIETZSCHE, FP 1887-9, 14(40), XIII, 1999, p. 238).

Sobre este aspecto Giacoia enfatiza a: “(...) inscrição da violência no âmago do direito e da política, talvez o elemento fundamental daquilo que, em Nietzsche, poderíamos reconhecer como uma filosofia do direito." (GIACOIA, 2014, p. 79). Na medida em que a violência e a guerra, enquanto disposições internas do indivíduo, forem apontando os caminhos da cultura, a vida continuará sendo afirmada. Entendida neste contexto, a 
vida é um campo agonístico que se subtrai a toda e qualquer influência massificadora imposta pelos padrões sociais. Urge, portanto, superar estes padrões sociais, o que se pode realizar por uma tomada de consciência sobre a cultura. A consciência cultural, em termos nietzschianos, refere-se à capacidade de percepção dos mecanismos massificadores que impedem a expressão da multiplicidade original da psicologia individual. Aqueles traços próprios do indivíduo, seu tipo psicológico, passa a ser dissolvido na massa gregária. O resultado disso não é outro senão a submissão a um modelo estabelecido sob os grilhões de uma grande razão uniformizadora e sistematizadora. Portanto, uma vida que se inclina passivamente a essa razão é uma vida enferma, necessitando assim operar uma auto superação, pela sua capacidade de afirmação, ao que Nietzsche atribui o estado de uma grande saúde. Pela grande saúde o indivíduo é elevado para além dos mecanismos uniformizadores que rebaixam, submetem e tornam culpado. Pergunta-se, em que medida a justiça, para além de sua compreensão igualitária, é capaz de sobrepujar a consciência de culpa?

Ao recorrer ao método genealógico a respeito de como surgiu a má consciência, Nietzsche retrocede até a pré-história, na base e fundamento da relação entre credor e devedor. Portanto, um sentimento moral, que, inscritos num tempo e num espaço, deixam de remeter a uma fundamentação metafísica para se alocarem em uma cultura e em uma história socialmente determinadas. A esse respeito Scarlett Marton se pronuncia afirmando que os sentimentos morais: “(...) surgem, modificam-se e, por vezes, desaparecem. Tendo uma origem e uma história, acham-se também relacionados com a organização social dos indivíduos, de forma que em diferentes sociedades existiram diferentes morais." (MARTON, 2000, p. 75). É no quadro do procedimento genealógico que Nietzsche submete essa nova maneira de conceber os sentimentos morais. As diferentes morais remetem a diferentes formas de relações sociais, nas quais vão se produzindo diferentes valores.

A noção nietzschiana de valor opera uma subversão crítica: ela põe de imediato a questão do valor dos valores e esta, 
ao ser colocada, levanta a pergunta pela criação dos valores. Se o valor dos valores 'bem' e 'mal' não chegou a ser posto em questão, é porque eles foram vistos como existindo desde sempre: instituídos num além, encontravam-se legitimamente num mundo supra-sensível. No entanto, uma vez questionados, revelam-se apenas 'humanos, demasiado humanos. (MARTON, 2000, p. 79).

Destas relações humanas, das quais emanam os valores e, dentre estes, o da dívida, se depreende a garantia da existência da comunidade. Ou seja, mediante os sacrifícios realizados pelos antepassados, o que faz com que as gerações subsequentes se sintam em uma obrigação moral para com elas, não cessa o sentimento de estar devendo algo a elas, num sentimento de culpa. Essa dívida gera um medo para com estes ancestrais, a ponto de convertê-los em divindades. Partilhamos, neste ponto, do comentário que Giacoia faz a respeito da gênese do universo moral e religioso a partir da esfera jurídica, de onde se depreende a relação dívida e culpa. "Como se percebe, a gênese da religião, bem como da moralidade em geral, é descortinada por Nietzsche a partir de categorias jurídicas, e não o contrário. Portanto, direito e moralidade não surgem do universo do sagrado e do religioso; ao contrário, os primórdios da religião se encontram no campo do direito obrigacional." (GIACÓIA, 214, p. 84).

\section{Considerações Finais}

A partir do sentimento jurídico da dívida e do medo, Nietzsche identifica a própria origem dos deuses. Uma origem, portanto, estabelecida sob a crença numa dívida contraída em rebanho que, à medida em que passa o tempo, aumenta o preço a pagar, e, com isso, aumenta a consciência de culpa. Uma consciência má como herança deixada pelas comunidades tribais. Ao se adaptarem ao culto dos senhores, os escravos e servos da gleba herdaram um sentimento de obrigação para com um ancestral comum. Com o passar do tempo, esse sentimento só veio a crescer, a ponto de se exacerbar o sentimento de Deus. (NIETZSCHE, GM, § 20, V, 1999, p. 330). 
Este sentimento, somado ao processo de fusão étnica, de revoluções culturais, de guerras, num caminho que se abre para a universalização, anulou a pluralidade dos deuses para se impor um modelo monoteísta, um Cristianismo que se considera "(...) desde o início, uma formação agregada a partir de construtos doentios que se reúnem e se buscam ..." (NIETZSCHE, FP 1887-9, 14(91), XIII, 1999, p. 267-8).

O máximo de poder e despotismo do Deus monoteísta, reflexo de uma sociedade universal padronizada, faz aumentar o sentimento de culpa, o que constitui a base de um movimento para trás, o ressentimento. "Negação e oposição: essa é a lógica da moral do ressentimento." (MARTON, 2000, p. 80). Nesta lógica é impossível se admitir o forte. "(...) o ressentimento imputa-lhe justamente o erro de ser forte. Reúne fatos e testemunhas para montar sua peça de acusação, cujo objetivo último é o de introduzir no âmago do forte o vírus corrosivo da culpa." (MARTON, 2000, p. 81). Uma culpa gerada, alimentada e fortalecida pelo sentimento de se estar em dívida com Deus.

Assim, se com o teísmo veio a culpa em lugar da primeira inocência, com o ateísmo vem a segunda inocência, pela rejeição do sentimento de culpa, que é o motor da má consciência. O estabelecimento da segunda inocência equivale a um recuo até a idade em que os povos mantinham sua convivência com as chamadas "divindades domésticas." Aquelas com quem se convivia no dia a dia sem o vínculo de algum imperativo universal. Nietzsche detecta na atenuação das redes sociais entre povos uma minimização do grau de má consciência. Um império universal causa despotismo e perda dos lastros individuais singulares. O indivíduo singular é sacrificado em função de uma culpa universal, a culpa da civilização. "A capacidade para a culpa, aquele 'instrumento' da 'má consciência', foi o desenvolvimento interno na história humana que permitiu alguma medida de controle social e, subsequentemente, a emergência da civilização." (GREER, 2002, p. 08). O que, no Cristianismo, passa a se tornar a mais forte expressão: - pelo pecado de um (Adão) todos pecaram, logo é novamente um (Cristo) o que assume a culpa de todos. Vânia Dutra de Azeredo, inclusive, 
reforça o peso que a interpretação cristã da culpa exerce sobre a consciência: "O desenvolvimento da culpa, na interpretação de Nietzsche, está diretamente relacionado com o advento do Deus cristão, por este fazer do homem alguém responsável por uma falta, fazendo da própria noção de responsabilidade algo culposo." (AZEREDO, 2003, p. 164).

Mediante o Cristianismo, a culpa assume um caráter institucional, fazendo com que a má consciência seja acentuada a ponto de não se vislumbrar nenhuma saída possível. $\mathrm{O}$ mal-estar que daí se deriva atinge uma proporção civilizacional cuja base é a moral. Pelos mecanismos gregários da moral, ao se utilizar de uma grande razão padronizadora e sistematizadora, se promove prostração, degenerescência e enfermidade, em detrimento do abandono da originalidade singular afirmativa do indivíduo, de quem unicamente brota uma grande saúde, a base de um mundo possível.

\section{Referências}

APOLINÁRIO, José António Feitosa. A genealogia do mal-estar: civilização e moral em Nietzsche e Freud. In: Revista Reflexões-Ce, Ano2, n. 2, Janeiro a junho de 2013.

AZEREDO, Vânia Dutra de. Nietzsche e a dissolução da moral. Ijuí: Editora Unijuí, 2003.

GIACOIA, Oswaldo Jr. Nietzsche. O humano como memória e como promessa. $2^{\mathrm{a}}$ ed. Petrópolis: Editoras Vozes, 2014.

GREER, Scott. Freud's 'Bad conscience': The case of Nietzsche's Geleaogy. Journal of History of the Behavioral Sciences, Vol. 38(3), 303-315 Summer 2002 .

HÖFFE, O. "Einführung in Nietzsches 'Genealogie der Moral". (pp. 1-14). In: O. Höffe (ed.). Friedrich Nietzsche. Zur Genealogie der Moral. Berlin: Akademie, 2004.

MARTON, Scarlett. Das forças cósmicas aos valores humanos. Belo Horizonte: Editora UFMG, 2000. $\overline{2004 .}$

. A irrecusável busca de sentido. São Paulo: Ateliê Editorial,

NIETZSCHE, F. W. Genealogie zur Moral. In: COLLI, von Giorgio; MONTINARI, Mazzino (Herausgegeben). Kritische Studienausgabe. Berlin: Verlag de Gruyter, 1999. Bd. 5. 
. Genealogia da Moral. Uma polêmica. São Paulo: Companhia das Letras, 2001.

. Nachgelassene fragmente: Herbst 1887 bis März 1888. In:

COLLI, von Giorgio; MONTINARI, Mazzino (Herausgegeben). Achte Abteilung. Berlin: Walter de Gruyter, 1999. Bd. 13.

. Fragmentos Póstumos: 1887-1889. Vol VII. Rio de Janeiro: Gen/Forense Universitária, 2012.

ONATE, Alberto Marcos. O crepúsculo do sujeito em Nietzsche ou como abrir-se ao filosofar sem metafísica. Ijuí: Editora Unijuí, 2003.

VIARO, Renee Volpato. Da moral nietzscheana ao mal-estar freudiano. Algumas aproximações e decorrências éticas. In: Etilos Clínicos, São Paulo, v. 17, n. 2, jul./dez. 2012, 373-395. 